\title{
Morphogenesis of Poliovirus
}

\section{Demonstration of a New Intermediate, the Proviron}

\author{
CARLOS B. FERNANDEZ-TOMAS AND DAVID BALTIMORE \\ Department of Biology, Massachusetts Institute of Technology, Cambridge, Massachusetts 02139
}

Received for publication 21 June 1973

\begin{abstract}
Poliovirus-infected cells contain a previously unrecognized particle which appears to be an intermediate in virion synthesis and therefore has been named proviron. It sediments at about $125 \mathrm{~S}$, contains the three procapsid proteins, VP-0, VP-1, and VP-3, and has $35 S$ viral RNA. It is disrupted both by sodium dodecyl sulfate and EDTA but the RNA resists digestion by ribonuclease. Pulsechase experiments and studies employing the virus-specific inhibitor, guanidine, all indicate that the proviron is formed by combination of newly made RNA with the procapsid. Cleavage of VP-0 to form VP-2 and VP-4 follows formation of the provirion and would be the final step in poliovirus morphogenesis.
\end{abstract}

Poliovirus morphogenesis involves a series of steps in which the capsid proteins are processed by proteolysis and are aggregated into structures of increasing size (3). The capsid proteins are translated from the viral genome into a single polypeptide, called NCVP $1(14,22)$. This polypeptide is cleaved to generate three proteins: VP-0, VP-1, and VP-3 $(11,13,15,21)$. Units of increasing complexity consisting of equimolar amounts of these three proteins are then assembled and combined with RNA to form the finished virion.

We have previously presented evidence that the protein complex to which RNA is added is a completed shell called the procapsid which sediments at about $80 S(15)$. The latter stages of morphogenesis involve both union of the RNA and protein and a final proteolytic cleavage in which the VP-0 is split into VP-2 plus VP-4. The mature virion sediments at about $155 \mathrm{~S}$.

The present investigation is concerned with the isolation of a new poliovirus-specific ribonucleoprotein particle which appears to be a new intermediate in the pathway of poliovirus morphogenesis and which appears to be the immediate precursor of the virion. It consists of the procapsid proteins plus viral RNA and we have provisionally named it the provirion to denote its apparent role as the progenitor of the virion.

\section{MATERIALS AND METHODS}

The growth of suspended HeLa cells, their infection by type 1 poliovirus in the presence of $5 \mu \mathrm{g}$ of actinomycin $\mathrm{D}$ per $\mathrm{ml}$, and the analysis of virusrelated particles by means of sucrose gradient centrifugation have been previously described $(5,15)$. For analysis by polyacrylamide gel electrophoresis, purified virus and virus-related particles were disrupted by boiling for $5 \mathrm{~min}$ in a solution of $1 \%$ mercaptoethanol, $1 \%$ sodium dodecyl sulfate (SDS), and $15 \%$ glycerol. The solutions were then subjected to the Maizel and Laemmli modification of polyacrylamide gel electrophoresis (C. N. Cole and D. Baltimore, J. Mol. Biol., vol. 76, in press; 18, 19).

${ }^{3} \mathrm{H}$-leucine $(39 \mathrm{Ci} / \mathrm{mmol}),{ }^{14} \mathrm{C}$-leucine $(260 \mathrm{mCi} /$ $\mathrm{mmol}),{ }^{3} \mathrm{H}$-uridine $(40$ to $50 \mathrm{Ci} / \mathrm{mmol})$, and ${ }^{14} \mathrm{C}$-uridine $(50 \mathrm{mCi} / \mathrm{mmol})$ were obtained from New England Nuclear Corp.

\section{RESULTS}

Identification of the provirion. HeLa cells infected for $3 \mathrm{~h}$ with poliovirus were labeled for $30 \mathrm{~min}$ with ${ }^{3} \mathrm{H}$-leucine and for $15 \mathrm{~min}$ with ${ }^{14} \mathrm{C}$-uridine. Analysis of detergent-treated cytoplasmic extracts of these cells by sedimentation through a sucrose gradient revealed a number of different virus-related structures (Fig. 1). ${ }^{3} \mathrm{H}$ leucine was recovered in virions $(155 S)$, procapsid $(80 S)$, and low molecular weight material. ${ }^{14} \mathrm{C}$-uridine was incorporated into virions, viral ribonucleoprotein $(87 S)(6)$, and lower molecular weight material. Both labels also appeared in a structure not previously recognized which sedimented at about $125 \mathrm{~S}$. We call this structure the provirion, a designation we will justify by the evidence presented below.

Components of the provirion. The protein content of the provirion, labeled with radioactive leucine, was analyzed by polyacrylamide gel electrophoresis in the presence of SDS. Electrophoresis of provirion proteins mixed with either proteins of virion or procapsid (Fig. 2) showed that provirion contained the same 


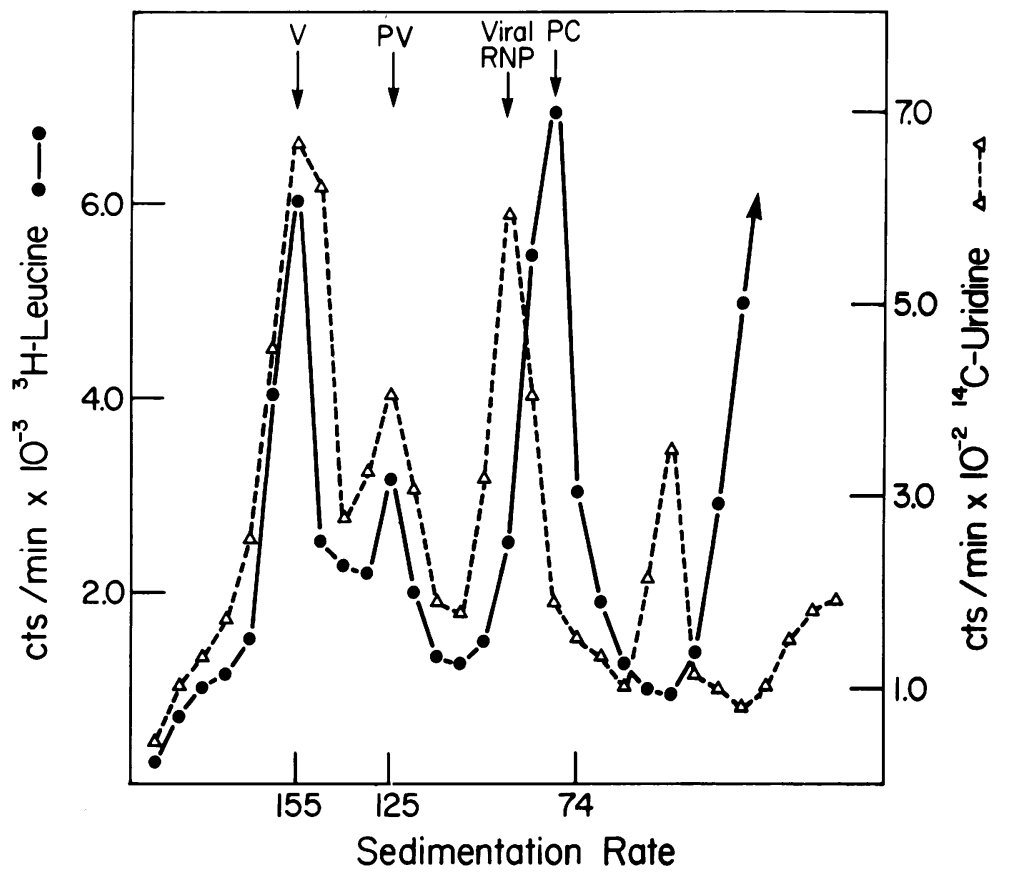

Fig. 1. Sucrose density gradient analysis of cytoplasmic extracts. At $3 \mathrm{~h}$ after infection, $4 \times 10^{7}$ cells were transferred to Earle saline (8), supplemented with ${ }^{3} \mathrm{H}$-leucine $\left.(20 \mu \mathrm{Ci} / \mathrm{m})\right)$; at $3 \mathrm{~h} 15 \mathrm{~min},{ }^{14} \mathrm{C}$-uridine $(1 \mu \mathrm{Ci} / \mathrm{ml})$ was added; at $3 \mathrm{~h} 30 \mathrm{~min}$, the cells were harvested by centrifugation and transferred to complete medium supplemented with 100-fold the normal concentration of leucine, and 5 min later a cytoplasmic extract in RSB (0.01 M Tris, $\mathrm{pH} \mathrm{7.4;0.01} \mathrm{M} \mathrm{NaCl;0.0015} \mathrm{M} \mathrm{MgCl}_{2}$ ) was prepared. To the extract was added $1 \%$ sodium deoxycholate and $1 \%$ BRIJ-58 and it was layered onto a linear 15 to $30 \%$ sucrose-RSB gradient and centrifuged at $95,000 \times g$ for $4 \mathrm{~h}$ in theSW 27 rotor at $4 C . A_{280}$ and radioactivity were determined in fractions from the gradients as described previously (5). Arrows indicate the position of virion (V), provirion (PV), procapsid (PC), and viral ribonucleoprotein $(v R N P)$.

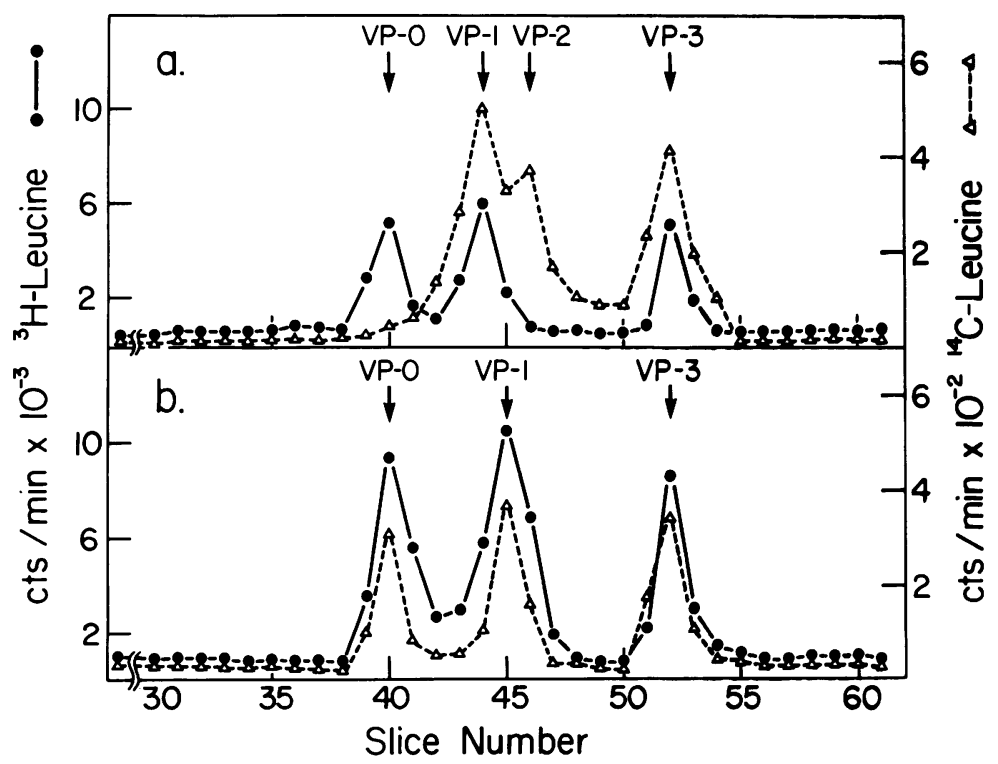

Fig. 2. Polyacrylamide gel electrophoresis of provirion proteins. Cells infected for $3 \mathrm{~h}$ were labeled with ${ }^{3} \mathrm{H}$-leucine or ${ }^{14} \mathrm{C}$-leucine for $30 \mathrm{~min}$ and cytoplasmic extracts were prepared and fractionated as described in Fig. 1. Samples of poliovirion, provirion, and procapsid were prepared for electrophoresis and analyzed on $10 \%$ acrylamide-ethylene diacrylate gels at $100 \mathrm{~V}$ for $6 \mathrm{~h}$. After electrophoresis, gels were removed from tubes, sliced, and radioactivity was assayed (C. N. Cole and D. Baltimore, J. Mol. Biol., in press). a, ${ }^{14} \mathrm{C}$-leucine-labeled virion and ${ }^{3} \mathrm{H}$-leucine-labeled provirion. $b,{ }^{3} \mathrm{H}$-leucine-labeled procapsid and ${ }^{14} \mathrm{C}$-leucine-labeled provirion. 
proteins as procapsid (VP-0, VP-1, VP-3) and was lacking the virion protein, VP-2.

The RNA of provirion was analyzed by sucrose gradient velocity sedimentation in the presence of a differentially labeled preparation of virion RNA (Fig. 3). Most of the provirion RNA sedimented indistinguishably from virion RNA.

Properties of the provirion. The stability of labeled provirion to various treatments was studied in order to provide an indication of the structure of the particle. When an extract of cells labeled with both uridine and leucine was treated with ribonuclease, the provirion was found to be stable to the enzyme (Fig. 4), indicating that the RNA of the particle is protected by the protein. (In this experiment, the peak of ribonuclease-resistant RNA at fraction 20 of Fig. 4B was presumably doublestranded RNA, much of which would arise from the replicative intermediate RNA, ref. 4.) Treatment of the isolated provirion with SDS caused its disruption (Fig. 5); as is evident in Fig. 5 and from previous studies (20), the virion is SDS-resistant. Treatment of the provirion with EDTA also disrupted it and liberated separated procapsid and viral RNA (Fig. 6). The virion is resistant to EDTA as evidenced by the small remaining peak of labeled virion in Fig. 6. The provirion is therefore a more labile structure than the virion, and divalent cations are important for maintaining its structure.

Provirion as precursor of virion. In order to investigate whether the provirion might be a precursor of the virion, a number of approaches were used. First of all, the labeling of procapsid and provirion in the presence of guanidine was studied. Guanidine is able to inhibit the production of any new viral RNA which can act as precursor to virion RNA $(1,2,12)$ and if provirion is on the pathway of virion production, one would expect that guanidine would inhibit its production. As seen in Fig. 7, cells labeled with ${ }^{3} \mathrm{H}$-leucine in the presence of guanidine and maintained in guanidine-containing medium did not synthesize any provirion although, in agreement with previous results (15), they did synthesize procapsid.

A second approach to the analysis of the role of provirion was a study of the kinetics of labeling of procapsid, provirion, and virion under conditions where virions were being produced. The experiment was performed by labeling cells with ${ }^{3} \mathrm{H}$-leucine in the presence of guanidine and then both adding an excess of unlabeled leucine and removing the guanidine. Figure 8a to e shows sucrose gradient profiles of samples taken at various times after exposure of cells to ${ }^{3} \mathrm{H}$-leucine. In the early samples, peaks of both provirion and virion of approximately

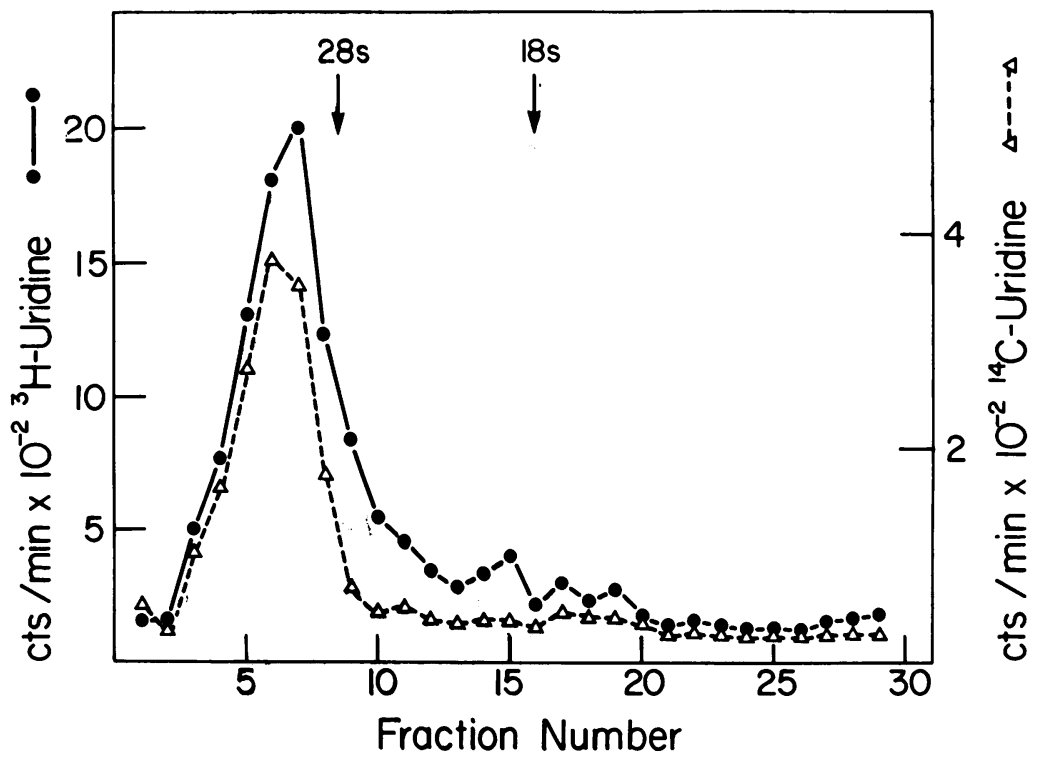

Fig. 3. Comparison of the sedimentation rates of virion and provirion RNA in sucrose SDS gradients. Labeled RNA was extracted by the acetic acid-SDS method $(10,20)$, mixed with unlabeled HeLa cell ribosomal $R N A$, layered over a 35-ml linear 15 to 30\% sucrose-SDS gradient, and sedimented for $15 \mathrm{~h}$ at $95,000 \times \mathrm{g}$ in the $S W-27$ rotor at 22 C. Fractions of $1 \mathrm{ml}$ were collected and analyzed for both $A_{280}$ and radioactivity. Symbols: $\Delta$, ${ }^{14} \mathrm{C}$-uridine virion; $\mathrm{O},{ }^{3} \mathrm{H}$-uridine provirion. 


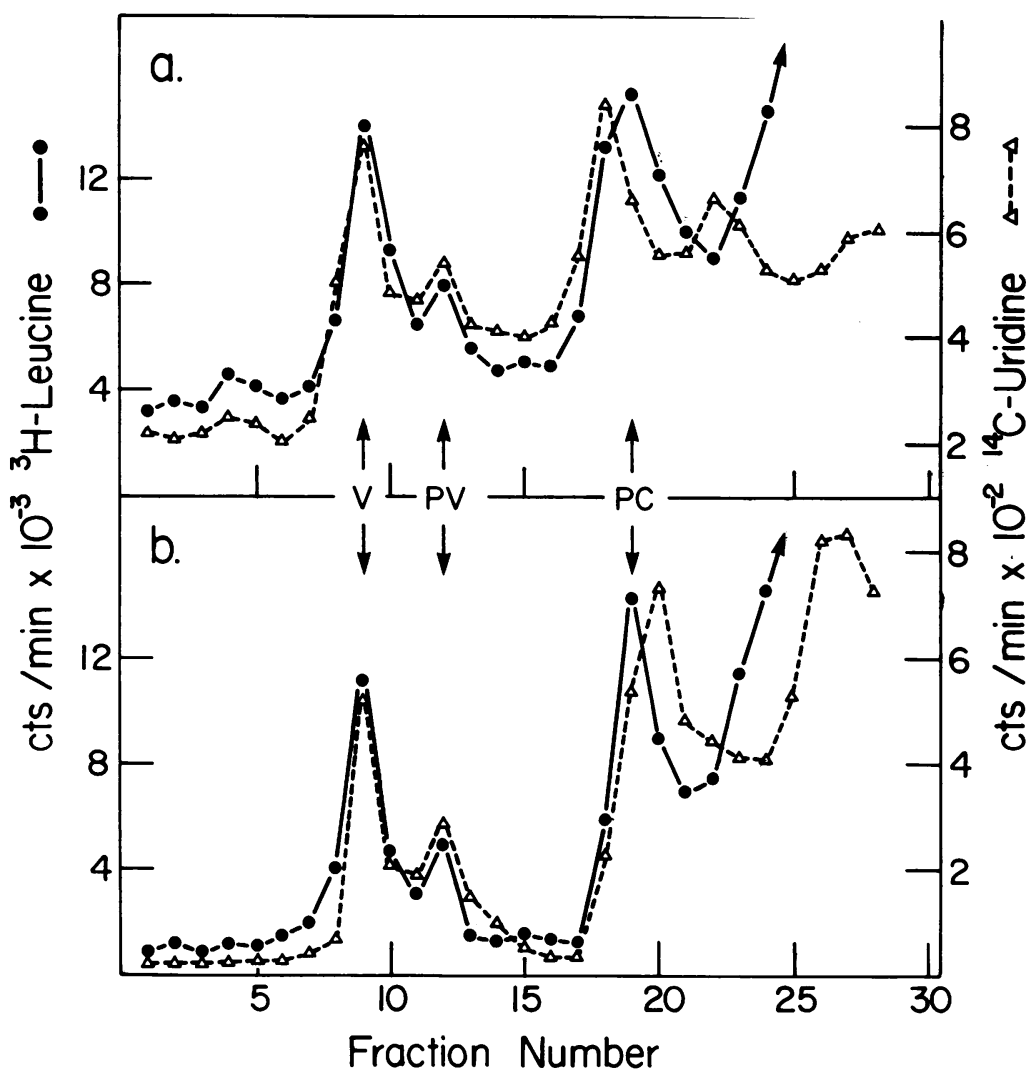

Fig. 4. Effect of ribonuclease on the provirion. At $3 \mathrm{~h} 30 \mathrm{~min}$ after infection, a cytoplasmic extract was prepared from $4 \times 10^{7}$ cells labeled with ${ }^{14} \mathrm{C}$-uridine $(1 \mu \mathrm{Ci} / \mathrm{ml})$ for $15 \mathrm{~min}$ and ${ }^{3} \mathrm{H}$-leucine $(20 \mu \mathrm{Ci} / \mathrm{ml})$ for $30 \mathrm{~min}$. It was adjusted to $0.3 \mathrm{M} \mathrm{NaCl}, 0.03 \mathrm{M} \mathrm{Na}$ citrate, and half was exposed to pancreatic ribonuclease $\mathrm{A}(10 \mu \mathrm{g} / \mathrm{ml})$ for 5 min at $37 \mathrm{C}$. Samples were analyzed on 15 to $30 \%$ sucrose gradients in $0.3 \mathrm{M} \mathrm{NaCl}, 0.03 \mathrm{M} \mathrm{Na}$ citrate, as described in Fig. 1. a, Not exposed to ribonuclease; b, cytoplasmic extract exposed to ribonuclease.

equal height were observed. As time passed, the amount of virion increased relative to provirion. The quantitation of this data is shown in Fig. $8 \mathrm{~F}$. Here it is evident that with time the amount of label in procapsid decreased, whereas the amounts in both virion and provirion increased. Initially, label in provirion increased more rapidly than in virion. At later times, the labeling of provirion began to reach a plateau. These kinetics are consistent with the provirion being a precursor of the virion. In this experiment, the total amount of label in the three particles increased slightly over the period of sampling because there was continual generation of procapsid from the polypeptides labeled during the exposure to ${ }^{3} \mathrm{H}$-leucine.

In a third type of experiment, cells were exposed to ${ }^{3} \mathrm{H}$-leucine, and labeled virion, provirion, and procapsid were allowed to form. Then guanidine was added to the cells. Samples were taken at various times and analyzed on sucrose gradients. Figure 9 shows that in the period after guanidine addition, radioactivity in provirion disappeared from the sucrose gradient pattern. Graphic representation of the data from this experiment (Fig. 10) showed that the decrease in radioactivity in provirion was paralleled by an approximately equal increase of radioactivity in virion, strongly supporting the concept that provirion is a precursor of virion. Radioactivity in procapsid continued to increase after guanidine treatment as would be expected from earlier results (15).

\section{DISCUSSION}

Analyses of poliovirus-infected $\mathrm{HeLa}$ cells have revealed a previously undetected, virusspecific particle sedimenting at about $125 S$. This particle, which we call the provirion, is labeled with both uridine and leucine-the uridine is found in viral RNA molecules, the leucine is found in the three procapsid proteins, 


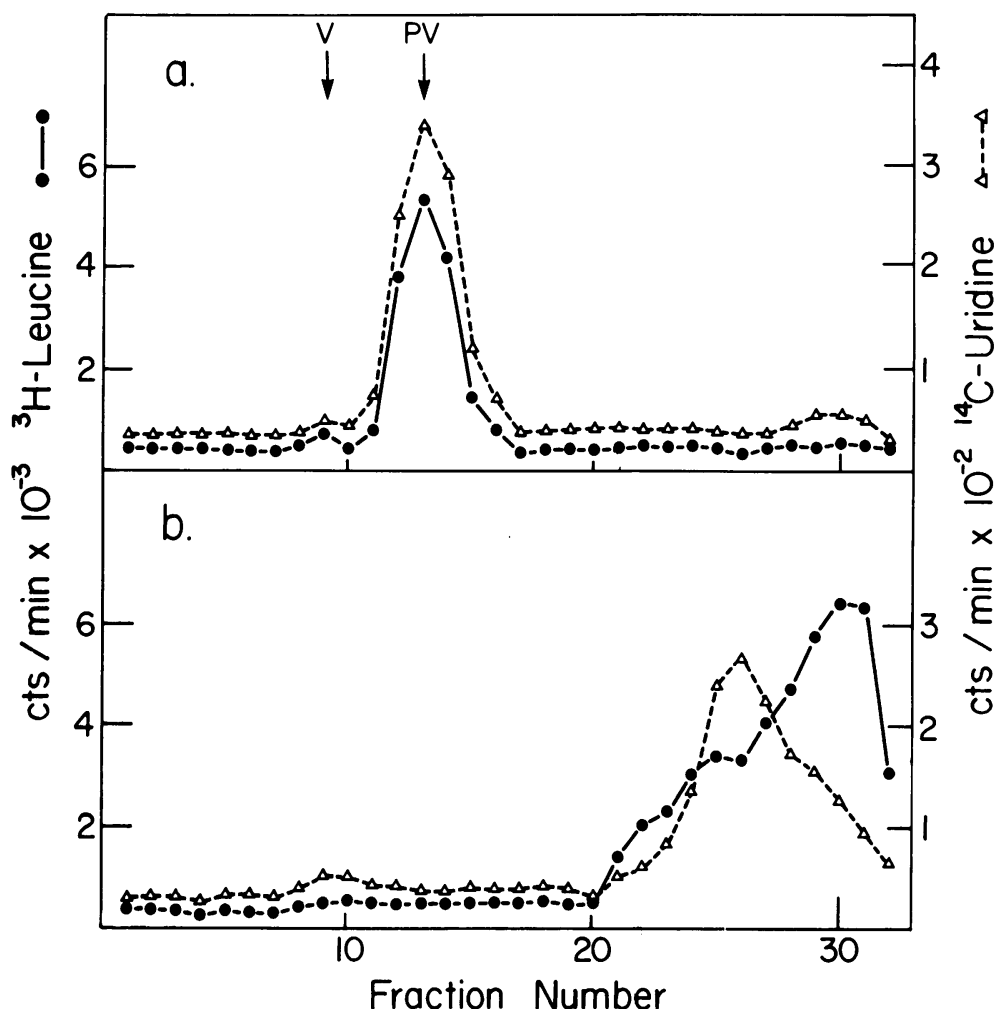

Fig. 5. Disruption of provirion by SDS. Labeled cytoplasmic extracts were made as described in Fig. 4, and provirion purified on a sucrose gradient. Fractions containing provirion were harvested; half of the sample was made $0.5 \% S D S$ and the other half remained in $R S B$. Samples were layered onto a linear sucrose-RSB gradient and analyzed as described in Fig. 1. a, Provirion not exposed to SDS; b, provirion exposed to SDS.

VP-0, VP-1, and VP-3. The provirion is less stable than the virion to various treatments. Like the procapsid, it is sensitive to SDS. Its sensitivity to EDTA is its most unique characteristic and may explain why it has not been noticed previously. The RNA of the particle resists digestion with ribonuclease, suggesting that the RNA is interior to and protected by the protein. Because the particle is unstable in $\mathrm{CsCl}$ we have not been able to ascertain its buoyant density.

The role of provirion as a precursor to the virion cannot be rigorously proven by in vivo kinetic experiments but a number of results are consistent with such a role and very special circumstances would have to pertain if it is not a precursor. First, its structure is just that of precursor-it contains viral RNA and procapsid proteins and it needs only the final cleavage of VP-0 to become a virion. Second, the movement of leucine into provirion requires the concomitant synthesis of viral RNA-guanidine blocks morphogenesis at the stage of procapsid. Third, in a pulse-chase experiment with ${ }^{3} \mathrm{H}$-leucine, radioactivity accumulates in provirion before virion and radioactivity in provirion starts to reach a plateau while that in virions is rising. Such behavior is what would be expected for a precursor. Fourth, ${ }^{3} \mathrm{H}$-leucine-labeled provirion disappears after guanidine addition and labeled virions continue to appear only as long as provirions contain radioactivity. Together, these experiments strongly suggest that the provirion is the direct precursor of the virion. Probably, only in vitro experiments can prove this assertion unambiguously.

Previous evidence indicated that the procapsid is the protein precursor of the virion (15). Even though this has not been rigorously proven, and procapsid is difficult to demonstrate in at least one poliovirus-infected cell system ( $\mathrm{MiO}$ cells) (9), it is striking that treatment of the provirion with EDTA leads to release of the RNA with an apparently intact procapsid as the product. Whatever the process involved in release of the RNA, its occurrence makes it easier 


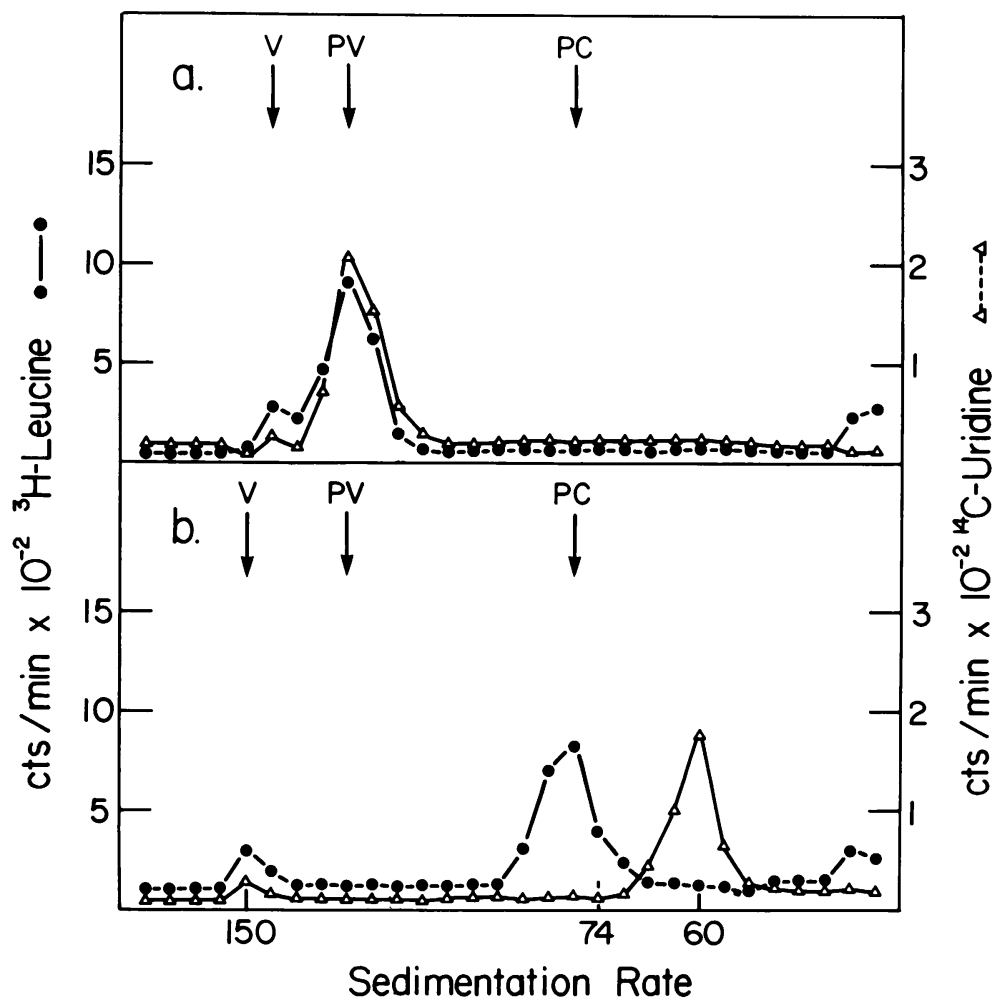

Fig. 6. Effect of EDTA on the provirion. Provirion labeled with ${ }^{14} \mathrm{C}$-uridine and ${ }^{3} \mathrm{H}$-leucine was isolated as described in Fig. 5. Half of the sample was exposed to $0.02 \mathrm{M}$ EDTA and layered onto a linear 15 to $30 \%$ sucrose gradient in 0.01 M Tris, pH 7.4,0.01 M NaCl, 0.02 M EDTA; the other half remained in $R S B$ and was layered onto a linear 15 to $30 \%$ sucrose-RSB gradient. Centrifugation was in the SW27 rotor, at $95,000 \times g$ for $4 \mathrm{~h}$ at $4 C$. Fractions were collected and radioactivity was determined. a, Provirion in $R S B ; b$, provirion exposed to EDTA. 


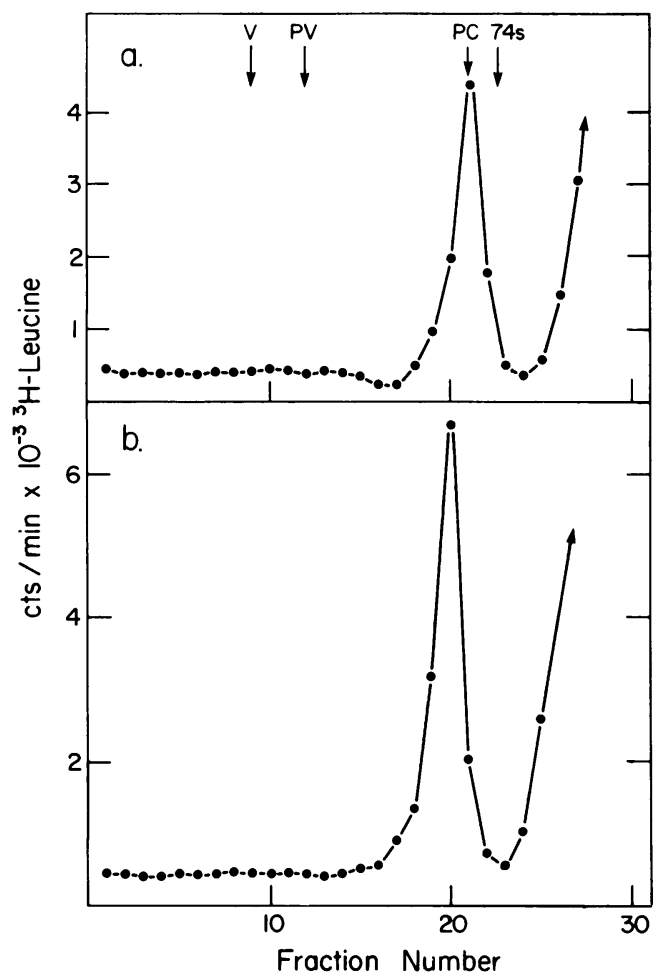

to imagine that the provirion forms by addition of RNA to the procapsid. Another model for this process is the release of turnip yellow mosaic virus RNA by urea, formamide, or interaction with cell receptors, which also leaves an apparently intact protein shell $(7,16,17)$. We would therefore interpret the available evidence as indicating that the penultimate step in virion maturation is association of the procapsid with viral RNA and the final step is cleavage of VP-0 to VP-2 plus VP-4. In this final step, the particle is converted from an SDS- and EDTA-sensitive form to a more stable configuration. Caliguiri and Compans (J. Gen. Virol., in press) have demonstrated that poliovirus morphogenesis occurs in association with a smooth membrane

Fig. 7. Absence of provirion synthesis in the pres ence of guanidine. A culture of $8 \times 10^{7}$ infected cells in $20 \mathrm{ml}$ of medium were transferred to Earle saline and treated with guanidine $(2 \mathrm{mM})$ at $3 \mathrm{~h}$ after infection. ${ }^{3} \mathrm{H}$-leucine $(20 \mu \mathrm{Ci} / \mathrm{ml})$ was added at $3 \mathrm{~h} 15 \mathrm{~min}$; at $3 \mathrm{~h} 35 \mathrm{~min}$ the cells were harvested by centrifugation and resuspended in complete medium supplemented with guanidine and 100 -fold the normal concentration of leucine; portions of $10 \mathrm{ml}$ were harvested 20 and 80 min later; cytoplasmic extracts were prepared and analyzed in sucrose- $R S B$ gradients as described in Fig. 1. a, At $20 \mathrm{~min}$; b, at $80 \mathrm{~min}$.

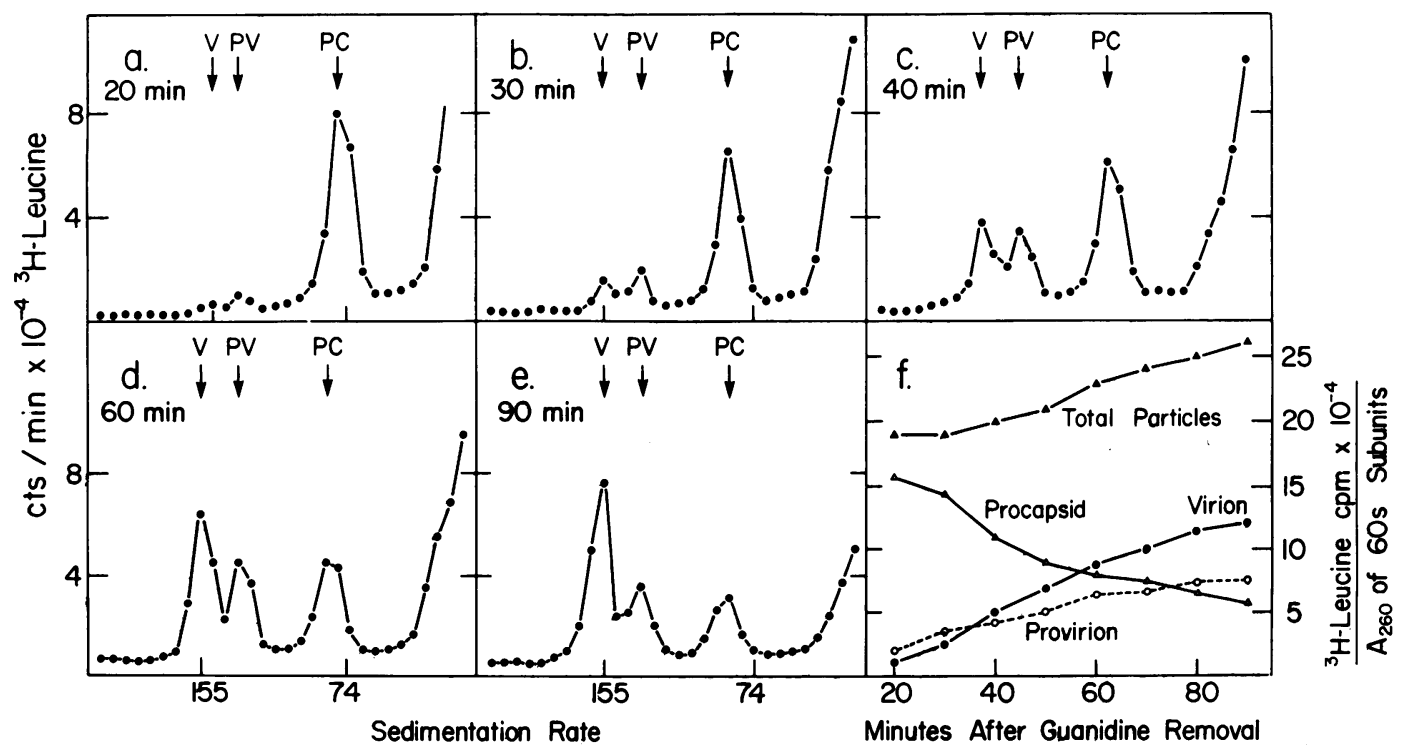

Fig. 8. Appearance of virion and provirion after accumulation of procapsid in the presence of guanidine. At 3 $h$ postinfection $3.2 \times 10^{8}$ infected cells were exposed to guanidine $(2 \mathrm{mM})$ for 15 min and then ${ }^{3} \mathrm{H}$-leucine $(20$ $\mu \mathrm{Ci} / \mathrm{ml}$ ) was added. After $15 \mathrm{~min}$ the cells were transferred to new medium supplemented with 100 -fold the normal concentration of leucine and lacking guanidine $(t=0)$. At various times, 10 -ml portions were harvested, cytoplasmic extracts were prepared, and they were analyzed as described in Fig. 1a to e. Samples taken at 20, $30,40,60$, and $90 \mathrm{~min}$, respectively. $f$, Normalized amount of radioactivity in the various particles. The amount of radioactivity in each peak was summed and the samples were normalized to the content of $A_{280}$ of $60 S$ ribosomal subunits. The total radioactivity in virus-specific particles was determined by summing the normalized values. 


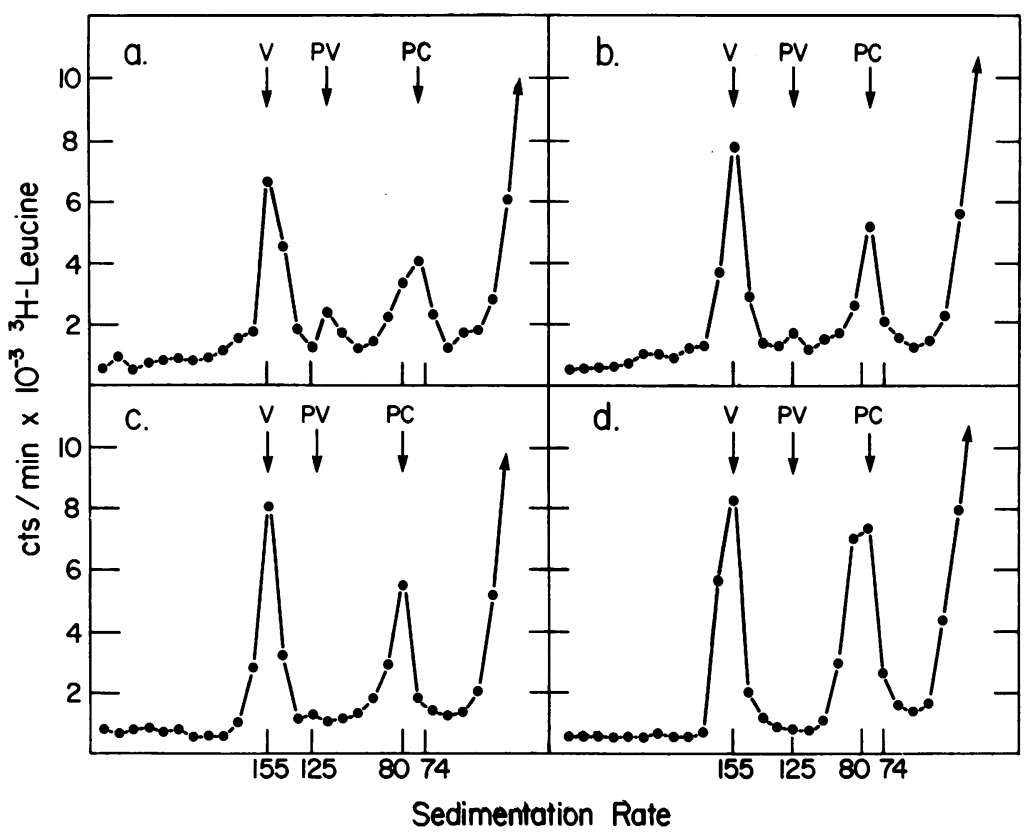

FIG. 9. Disappearance of provirion after exposure of cells to guanidine. A culture of $2 \times 10^{\mathrm{s}}$ infected cells was exposed to guanidine $(2 \mathrm{mM})$ at $3 \mathrm{~h}$ postinfection, 15 min later ${ }^{3} \mathrm{H}$-leucine was added $(20 \mu \mathrm{Ci} / \mathrm{ml})$, and after 20 min guanidine was removed and cells were resuspended in complete medium supplemented with 100-fold excess of leucine. At $4 \mathrm{~h} 5 \mathrm{~min}$, guanidine was added $(t=0)$. Portions of $10 \mathrm{ml}$ were harvested at various times and cytoplasmic extracts were prepared and analyzed as described in Fig. 1a to d, Samples taken at 0, 5, 15, and 30 min, respectively.

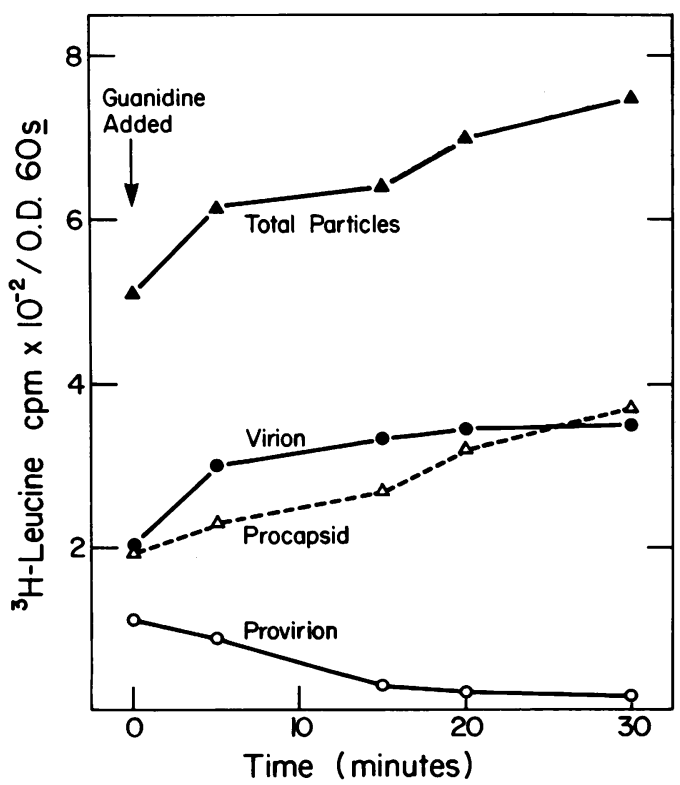

Fig. 10. Normalized radioactivity in particles after exposure of cells to guanidine. Radioactivity in virion, provirion and procapsid from experiment described in Fig. 9 were normalized to the content of $A_{280}$ of $60 S$ ribosomal subunit as described in Fig. 8, panel $f$. fraction. The viral RNA for virion formation therefore probably comes directly from its site of synthesis into the procapsid.

Formation of provirion can be detected in cell-free extracts (Fernandez-Tomas, Guttman, and Baltimore, J. Virol., 12:1181-1183). Formation of whole virions in such extracts has not yet been detected.

\section{ACKNOWLEDGMENTS}

We thank Donna Smoler for expert technical assistance and Alice Huang and Charles Cole for critical reading of the manuscript.

This investigation was supported by Public Health Service grant AI-08388 from The National Institute of Allergy and Infectious Diseases. C.B.F. was a post-doctoral fellow of the Damon Runyon Memorial Fund for Cancer Research and D.B. was an American Cancer Society research professor.

\section{LITERATURE CITED}

1. Baltimore, D. 1968. Inhibition of poliovirus replication by guanidine, p. 340-347. In M. Sanders and E. H. Lennette (ed.), Medical and applied virology, Proceedings of the Second International Symposium. Warren H. Green, Inc., St. Louis.

2. Baltimore, D. 1969. The replication of picornaviruses, p. 101-176. In H. B. Levy (ed.), The biochemistry of viruses. Marcel Dekker, New York.

3. Baltimore, D. 1971. Polio is not dead, p. 1-12. In M. Pollard (ed.), From molecules to man, perspectives in virology VII. Academic Press Inc. New York. 
4. Baltimore, D., and M. Girard. 1966. An intermediate in the synthesis of poliovirus RNA. Proc. Nat. Acad. Sci. U.S.A. 56:741-748.

5. Baltimore, D., M. Girard, and J. E. Darnell. 1966. Aspects of the synthesis of poliovirus RNA and the formation of virus particles. Virology 29: 179-189.

6. Baltimore, D., and A. S. Huang. 1970. Interaction of HeLa cell proteins with RNA. J. Mol. Biol. 47:263-273.

7. Bouley, J. P., and L. Hirth. 1968. Action de la formamide sur le virus de la mosaique jaune du navet: formation de capsides artificielles. C. R. Acad. Sci. Ser. D. 266:430433.

8. Earle, W. R. 1943. Production of malignancy in vitro. IV. The mouse fibroblast cultures and changes seen in the living cell. J. Nat. Cancer Inst. 4:165-173.

9. Ghendon, Y., E. Yakobson, and A. Mikhejeva. 1972. Study of some stages of poliovirus morphogenesis in MiO cells. J. Virol. 10:261-266.

10. Granboulan, N., and M. Girard. 1969. Molecular weight of poliovirus RNA. J. Virol. 4:475-479.

11. Holland, J., and E. D. Kiehn. 1968. Specific cleavage of viral proteins as steps in the synthesis and maturation of enteroviruses. Proc. Nat. Acad. Sci. U.S.A. 60: 1015-1022.

12. Huang, A. S., and D. Baltimore. 1970. Initiation of polyribosome formation in poliovirus-infected HeLa cells. J. Mol. Biol. 47:275-291.

13. Jacobson, M. F., J. Asso, and D. Baltimore. 1970. Further evidence on the formation of poliovirus proteins. J.
Mol. Biol. 49:657-669.

14. Jacobson, M. F., and D. Baltimore. 1968. Polypeptide cleavages in the formation of poliovirus proteins. Proc. Nat. Acad. Sci. U.S.A. 61:77-84.

15. Jacobson, M. F., and D. Baltimore. 1968. Morphogenesis of poliovirus 1 . Association of the viral RNA with coat protein. J. Mol. Biol. 33:369-378.

16. Jonard, G., and L. Hirth. 1966. Action de l'uree sur le virus de la mosaique jaune du navet. C. R. Acad. Sci. Ser. D. 263: 1909-1912.

17. Kurtz-Fritsch, C., and L. Hirth. 1972. Uncoating of two spherical plant viruses. Virology 47:385-396.

18. Laemmli, U. K. 1970. Cleavage of structural proteins during the assembly of the head of bacteriophage T4. Nature (London) 227:680-685.

19. Maizel, J. V., Jr. 1971. Polyacrylamide gel electrophoresis of viral proteins. p. 180. In K. Maramorosch and $\mathrm{H}$. Koprowski (ed.), Methods in virology, vol. 5, Academic Press Inc., New York.

20. Mandel, B. 1962. Early stages of virus cell interaction as studied by using antibody. Cold Spring Harbor Symp. Quant. Biol. ${ }_{\lambda}$ 27:123-136.

21. Summers, D. F., and J. V. Maizel, Jr. 1968. Evidence for large precursor proteins in poliovirus synthesis. Proc. Nat. Acad. Sci. U.S.A. 59:966-971.

22. Summers, D. F., J. V. Maizel, and J. E. Darnell. 1965 Evidence for virus-specific non-capsid proteins in poliovirus-infected HeLa cells. Proc. Nat. Acad. Sci. U.S.A. 54:505-513. 